\title{
Efficacy of praziquantel treatment regimens in pre-school and school aged children infected with schistosomes in sub- Saharan Africa: a systematic review
}

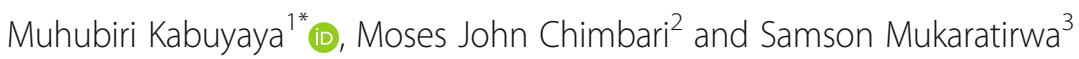

\begin{abstract}
Background: Schistosomiasis is a serious public health burden in sub-Saharan Africa. Praziquantel is the only drug recommended by the World Health Organization to treat both urogenital and intestinal schistosomiasis. The reliance on a single drug to treat a disease with such a huge burden has raised concerns of possible drug resistance mainly in endemic areas. This systematic review was conducted to identify gaps and recent progress on the efficacy of different regimens of praziquantel in treating schistosomiasis among children in sub-Saharan Africa where Schistosoma mansoni and S. haematobium are endemic.

Main text: A literature search of peer-reviewed journals was done on Google Scholar, MEDLINE (under EBSCOhost) and PubMed databases using pre-defined search terms and Boolean operators. The search included studies published from 2008 to 2017 (August) with emphasis on the efficacy of praziquantel on S. haematobium and S. mansoni infections among preschool and school children. Nineteen publications satisfied the inclusion criteria for the review. The studies reviewed were from 10 sub-Saharan African countries and $7 / 19$ of the studies (37\%) were conducted in Uganda. Seven studies (37\%) focused on Schistosoma mansoni, 6/19 (31.5\%) on S. haematobium and another 6 on mixed infection. A single standard dose of $40 \mathrm{mg} / \mathrm{kg}$ body weight was the most used regimen (9) followed by the repeated single standard dose assessed for efficacy at 3-4 weeks post-treatment.

Conclusions: A repeated standard dose of $40 \mathrm{mg} / \mathrm{kg}$ achieved satisfactory efficacy compared to a single dose against both parasite species. However, findings on efficacy of repeated doses in co-infection of $S$. mansoni and $S$. haematobium were not conclusive. Praziquantel administrated at $60 \mathrm{mg} / \mathrm{kg}$ was slightly more efficacious than the $40 \mathrm{mg} / \mathrm{kg}$ standard dose. Minor and transitory side-effects were reported for both regimens. The review indicates that further investigations are necessary to conclusively determine efficacy of praziquantel on coinfection of $S$. haematobium and S. mansoni to formulate concrete guidelines on the use of repeated doses at $40 \mathrm{or} 60 \mathrm{mg} / \mathrm{kg}$ for treating schistosomiasis. We recommend the use of the egg reduction rate (ERR) formula recommended by the WHO for assessing praziquantel efficacy in order for the results to be comparable for different regions.
\end{abstract}

Keywords: Praziquantel, Efficacy, Resistance, Schistosoma mansoni, Schistosoma haematobium, Sub-Saharan Africa

\footnotetext{
* Correspondence: muhubirikabuyaya@gmail.com

'Discipline of Public Health Medicine, Howard College, University of

KwaZulu-Natal, P.O Box 4041, Durban, South Africa

Full list of author information is available at the end of the article
} 


\section{Multilingual abstracts}

Please see Additional file 1 for translations of the abstract into six official working languages of the United Nations.

\section{Background}

Schistosoma infection is a worldwide public health problem, particularly in sub-Saharan Africa where approximately $90 \%$ of the infections are found [1]. Both Schistosoma haematobium and Schistosoma mansoni are responsible for the burden of the disease although $S$. haematobium is more prevalent in the sub-Saharan region. In 2012, at least 249 million people required preventive treatment and only 42.1 million were reported to have been treated [2]. To date, praziquantel administered at the standard single oral dose of $40 \mathrm{mg} / \mathrm{kg}$ body weight is the mainstay drug recommended by WHO for chemo-preventive therapy [2,3]. This dosage has been largely used in mass drug administration (MDA) programmes in endemic countries to reduce the morbidity of the disease [4].

In sub-Saharan Africa, studies have shown that praziquantel drastically reduces morbidity and transmission of schistosomiasis. It has a high cure rate (CR) and satisfactory egg reduction rate (ERR) [5, 6]. However, failure/ resistant cases have been reported after the use of a single standard dose of praziquantel at $40 \mathrm{mg} / \mathrm{kg}$ body weight. A repeated standard dose regimen has been shown to be more efficacious than the single dose [7]. Even when the repeated dose was used, few treated cases continued to release viable eggs. This prompted trials with a single dose of $60 \mathrm{mg} / \mathrm{kg}$ body weight to prevent failure/resistant cases. Researchers that conducted comparative studies of praziquantel with the standard dose of $40 \mathrm{mg} / \mathrm{kg}$ versus $60 \mathrm{mg} / \mathrm{kg}$ at a split dose [8, 9] reported divergent results. Belizario et al. reported similar efficacy on S. mansoni with both dose therapies [8] and significantly higher but mild and transient side effects with $60 \mathrm{mg} / \mathrm{kg}$ regimen [8]. In contrast, Coulibaly et al. showed that $60 \mathrm{mg} / \mathrm{kg}$ was more efficacious than $40 \mathrm{mg} / \mathrm{kg}$ [9].

Various factors such as species of parasite [7], parasite stage [10] and infection intensity have been attributed to influence the treatment outcomes with praziquantel with regard to the CR and ERR. Praziquantel is reported to be more efficacious on $S$. japonicum than it is on $S$. mansoni. S. haematobium has the lowest CR among mixed infections of S. haematobium and S. mansoni [7, 11]. It is also known that praziquantel is not effective on immature worms [12]. Moreover, schistosome resistance to praziquantel treatment following its repeated dose use has been reported in field studies [10].

Since there is no vaccine to prevent Schistosoma infection, regular monitoring of the efficacy of praziquantel is crucial. Studies on S. mansoni and S. japonicum focusing on the genetic diversity of the parasite as the determinant praziquantel efficacy have been conducted in Japan, China and the Philippines. Since praziquantel is not active on immature worms [12], a combination of praziquantel with antimalarial drugs (artemether, artesunate) which kill immature worms has been suggested as a comprehensive cure $[12,13]$. Phase 3 schistosome vaccine clinical trials are in progress [14]. In sub-Saharan Africa, where $S$. mansoni and $S$. haematobium are endemic, particularly among children, studies on the efficacy of praziquantel are limited and the few studies that investigated the relationship between morbidity due to $S$. haematobium and the genetic variation have reported conflicting results $[15,16]$. This highlights the need for further investigations on the efficacy/failure of different doses of praziquantel against $S$. haematobium and $S$. mansoni in endemic areas of sub-Saharan African. In this paper we reviewed the status of use of praziquantel and identified gaps in the treatment of schistosomiasis in the sub-Saharan region? Electronic searches focusing on the efficacy of different regimens of praziquantel in treating schistosomiasis among children in sub-Saharan Africa were done to extract literature on the subject.

\section{Main text \\ Review methods \\ Search strategy}

A systematic electronic search of literature on PubMed, MEDLINE and Google Scholar databases was carried out using following terms and Boolean operators: praziquantel AND efficacy AND resistance AND schistosomiasis AND Schistosoma haematobium OR Schistosoma mansoni AND sub-Saharan Africa. At the initial stage of identifying articles, titles and abstracts were used to screen relevant papers. Relevant abstracts were further assessed for inclusion in the list of full text articles. The full texts were further assessed for eligibility in the review. All records were managed in Endnote version X7 (Clarivate Analytics, Philadelphia, PA, USA). The review included research articles published within a 10 year period from 2008 to 2017 (August).

\section{Inclusion and exclusion criteria}

Publications in peer-reviewed journals that focused on field studies on the efficacy and resistance/failure of praziquantel on S. haematobium and S. mansoni treatment among children in sub-Saharan Africa were included in the review. Studies that reported on interventional studies conducted among children less than 18 years old were also included in the review. Studies in which praziquantel was administrated at $40 \mathrm{mg}$ single standard dose and/or repeated standard dose or at 
escalating dose $(20 / 40 / 60 \mathrm{mg} / \mathrm{kg})$ were added to the list of eligible articles.

The following studies were excluded:

- Reports on work that involving both children and adults;

- Studies that reported on the efficacy of praziquantel combined with other anti-schistosomal drugs;

- Studies that assessed the efficacy of praziquantel in the co-infection settings of schistosomiasis with other parasitic diseases like soil transmitted helminthic diseases;

- Laboratory experimental studies on praziquantel efficacy;

- Studies in which praziquantel efficacy was assessed after more than nine weeks post first administration.

Quality assessment of the studies was performed using the Study Quality Assessment Tool for Quality Assessment of Controlled Intervention Studies. Individual studies were assigned a score that was computed using different parameters in line with the review objectives. The responses were scored 0 for "No" and 1 for "Yes". Total scores ranged between 0 and $10 ; 1-4=($ Low $) ; 5-7=$ (Moderate) and 8-10 $=($ High $)$. The overall score was moderate.

\section{Results}

The literature search from Google Scholar provided one thousand two hundred and thirty (1230) records of which only 1010 were accessible. The search setting for ten results per page could not allow to go further than the $100^{\text {th }}$ webpage. We obtained 463 records from the PubMed database and sixty eight (68) from MEDLINE. Overall, the electronic search provided a total of $n=1541$ hits (Fig. 1). Hundred and ninety duplicate articles were removed from the records. During the screening of titles 1315 were deemed ineligible based on their relevance and the language in which they were published. Therefore, they were excluded from the screening process for abstracts. Out of the remaining 36 abstracts that were deemed relevant, 13 were excluded as they did not focus specifically on the efficacy of praziquantel against $S$. haematobium and/or S. mansoni in sub-Saharan Africa in a field setting. This gave a total of 23 studies eligible for full text screening. The review included interventional studies (cohort and randomised control). Excluded studies were those that reported either on the efficacy of praziquantel in combination with other medications or experimental laboratory studies or reviews. Studies in which the study population comprised children and adults were also excluded. Out of the twenty three studies whose full texts were reviewed, three were removed as the time line of assessing for praziquantel efficacy did not meet the inclusion criteria (3-9 weeks). An additional study was removed as it was published in 2008 but was carried out in 2004. Therefore, nineteen (19) publications were deemed relevant for final inclusion and were reviewed (Fig. 1).

\section{Efficacy of praziquantel by age group}

The reviewed studies were conducted among children. School-going children were the most represented (eight studies) followed by pre-school children (seven studies). Four studies involved both age groups. The highest number of the studies (nine) were conducted between 2012 and 2013.

The cure rate had been largely used in assessing praziquantel efficacy in the past. The use of the egg reduction rate was recently recommended [17]. In most studies that were carried out among school going children, the efficacy of praziquantel improved significantly after the repeated standard dose of $40 \mathrm{mg} / \mathrm{kg}$ body weight [1823]. Higher cure rates were observed among people infected with $S$. mansoni those infected with $S$. haematobium infection [24]. Pre-school children were included among the target group for schistosmiasis treatment after realizing that they were a high risk group as well. [25]. Praziquantel administered at $40 \mathrm{mg} / \mathrm{kg}$ single dose demonstrated satisfactory efficacy among children [2628]. Efficacy was lower in children that received multiple rounds of praziquantel treatment than in those that did not receive any treatment before [29]. In response to the pressing need of standardizing treatment in pre-school children, alternative paediatric forms of praziquantel have been on trial. Crushed praziquantel has been reported to have satisfactory efficacy for all species [30] while praziquantel syrup (Epiquantel ${ }^{\circ}$ ) showed diminished efficacy [31] for reasons not known.

\section{Distribution of studies by country and species}

Of the 19 studies reviewed, the majority of them $(7 / 19=$ $37 \%)$ were carried out in Uganda where S. mansoni was the predominant species (Additional file 2: Table S1). Another study on S. mansoni infection carried out in Ethiopia [19] indicated an East Africa dominance in distribution of S. mansoni. Elsewhere in other countreis of sub-Saharan Africa $S$. haematobium and mixed infections were found (Additional file 3: Table S2 and Additional file 4: Table S3). As shown in Additional file 4: Table S3, of the 6 mixed infections that were reported, 2 were from Niger [31, 32] and one from Cameroun, Ivory Coast, Senegal and Zimbabwe [23, 24, 28, 30]. The rest of the infections were due to $S$. haematobium (Additional file 3: Table S2).

\section{Efficacy of praziquantel on S. haematobium and S. mansoni}

S. haematobium and S. mansoni both exist separately or in co-infection in sub-Saharan countries. Praziquantel is 


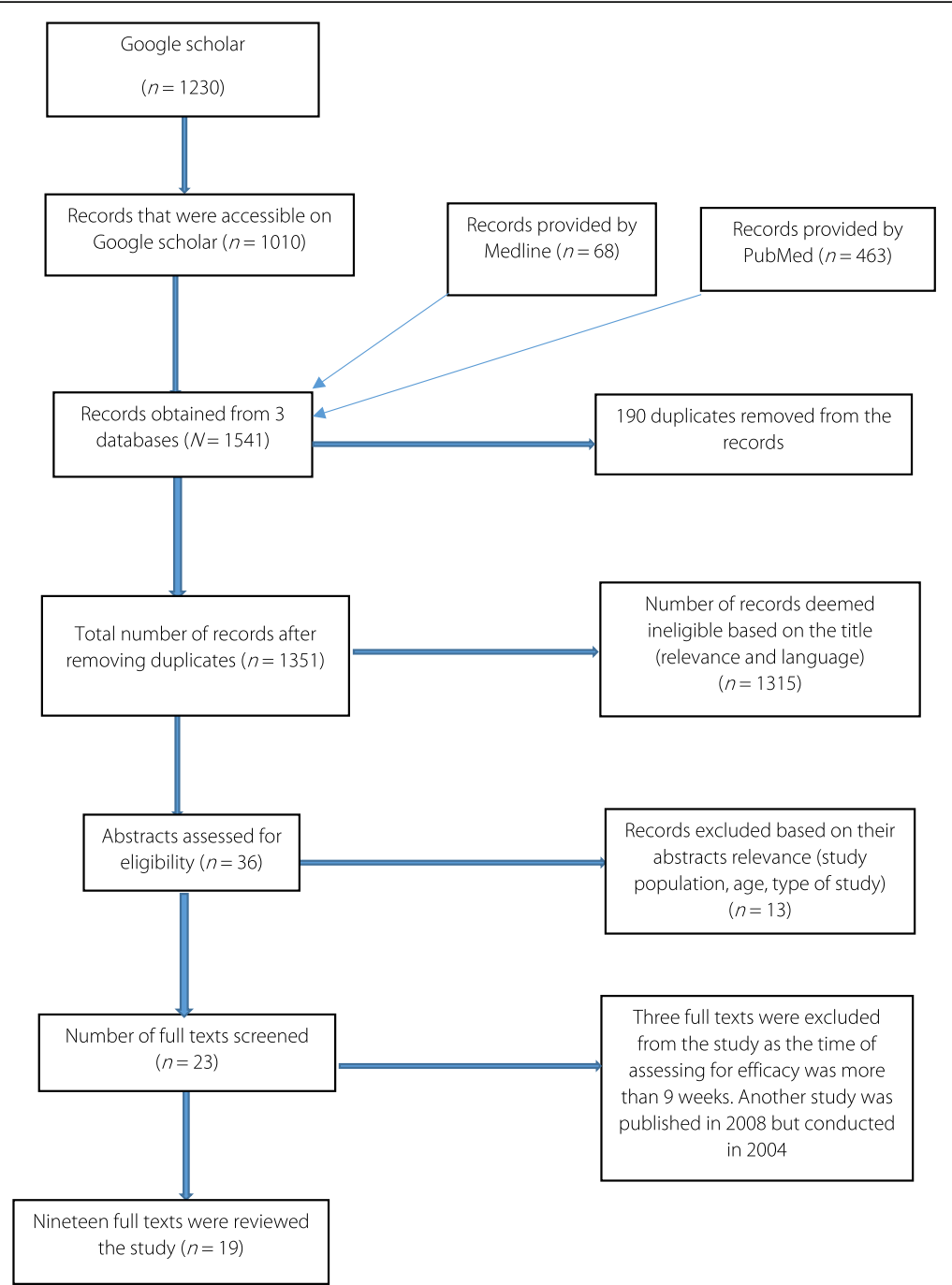

Fig. 1 PRISMA diagram showing the process of studies search. PRISMA: Preferred Reporting Items for Systematic Reviews and Meta-Analyses

efficacious on all species, therefore, it is the only recommended drug for preventing and treating schistosomiasis [2] despite some observed low cure rates and possible resistance recently reported. This review shows that for most of the studies praziquantel had high efficacy on both species [19, 22, 27, 28, 29, 34]. However, higher efficacy was reported against S. haematobium [30-32] than it was with S. mansoni [24] in co-infection settings as shown in Additional file 4: Table S3.

\section{Efficacy of different dose regimens of praziquantel}

Praziquantel administered at $40 \mathrm{mg} / \mathrm{kg}$ body weight is the standard dose recommended by WHO for chemotherapy in treating schistosomiasis. Articles reviewed mainly reported on the efficacy of different dosages of praziquantel used against both S. haeamtobium and/or $S$. mansoni in sub-Saharan Africa. Most studies used single dose $(9 / 19,47 \%)$ followed by studies that used single dose versus repeated standard dose $(6 / 19,32 \%)$. Repeated standard dose was administered in three studies while one study used the escalating dose $(20 / 40 / 60 \mathrm{mg} /$ $\mathrm{kg})$. The efficacy of praziquantel varied significantly depending on whether it was single or repeated dose. Overall, the repeated dose was more efficacious compared to the single dose. Cure rates and egg reduction rates were low or moderate after the single dose and improved after the administration of the second dose [23, $27,31-33]$. In some studies, praziquantel given at single dose revealed high cure rates and egg reduction rates $[19,28,34,35]$ while they were low in others $[31,36]$. Escalating dose of praziquantel was more efficacious at high dose than at low dose [9].

\section{Discussion}

The study reviewed the efficacy of different doses of praziquantel against $S$. mansoni and S. haematobium 
infection in endemic settings in sub-Saharan Africa. Our discussion is based on the used dose, the targeted species and the time of assessment post-treatment. An emphasis was also given to studies conducted in high endemic zones where several rounds of mass drug administration were done.

Praziquantel administered at a standard dose of 40 $\mathrm{mg} / \mathrm{kg}$ was shown to be effective against Schistosoma infection. However, a low cure rate that may require a second or high dose to clear the infection was reported [36]. This may be because praziquantel kills mature schistosomes while immature worms are not affected but later become mature and release eggs at a later stage. Infection may also persist after praziquantel treatment due to the reduced susceptibility of juvenile parasites to the drug [37]. Such persistent infections may then contain a significant amount of juvenile schistosomes that are refractory to praziquantel at the standard dose leading to lower cure rate and egg reduction rate. In high endemic areas where school-going children had been subjected to several rounds of mass drug administration (MDA), it was evident that praziquantel at the standard dose was less efficacious among those that received higher rounds of praziquantel (8 to 9) compared to those that received lesser rounds of treatment (1 and 5) [38]. Thus, the use of praziquantel in MDA campaigns has raised concerns on the possibility of development of drug resistance. It is however important to realize that the parasite may acquire tolerance to praziquantel that needs to be distinguished from resistance. Repeated doses of praziquantel have been reported to improve the outcomes of infection, post treatment [7]. Follow-ups after large scale intervention such as MDA are needed since praziquantel is the only recommended drug for schistosomiasis at $40 \mathrm{mg} / \mathrm{kg}$ body weight and in most cases does not completely clear the parasite.

Studies that used repeated standard dose of praziquantel $[20,33]$ showed satisfactory efficacy after the second dose. These findings corroborate with those found in another study [7]. Administration of the second dose was intended to target immature worms missed by first treatment and that was done 3-4 weeks following the initial treatment. Moreover, the outcomes of praziquantel efficacy varied depending on whether it was a single infection or mixed infection. Studies that focused on one species reported satisfactory efficacy [20, 33, 39] while those focused on co-infection (S. haematobium and $S$. mansoni) had inconsistent results [24,32]. The period of assessment between the first dose and follow up might have not been sufficient to allow complete release of dead eggs from the human host. However, the underlying cause of this reduced efficacy among mixed infection needs to be elucidated. Despite the use of the second dose, few refractory cases were still observed.
Schistosome infections may persist after the treatment due to the reduced susceptibility of immature parasites to the drug [37] and may develop tolerance or resistance over time. This may be the same mechanism that schistosomes acquire tolerance/resistance in endemic areas after several rounds of MDAs.

In a study that used an escalating dose, the outcomes of praziquantel efficacy gradually improved with increasing dosage [9]. The initial dose of $20 \mathrm{mg} / \mathrm{kg}$ body weight was lower than the recommended dose of 40 $\mathrm{mg} / \mathrm{kg}$ to kill schistosomes and showed low efficacy. Consistent with the above, results from a laboratory experiment showed that the use of praziquantel, especially at a lower dose than the recommended curative dose may lead to development of resistance to the drug in future generations [40]. Another study that compared praziquantel given at $40 \mathrm{mg} / \mathrm{kg}$ and $60 \mathrm{mg} / \mathrm{kg}$ single doses reported satisfactory efficacy with both regimens. However, there was no significant difference between the doses but more minor and transient side effects were observed at $60 \mathrm{mg} / \mathrm{kg}$ regimen [8].

This review showed that praziquantel was efficacious on both S. haematobium and S. mansoni with the former being more sensitive to praziquantel. In another comparative study, the efficacy of praziquantel was shown to be higher against $S$. japonicum than other species [11]. Factors responsible for this difference are not clear and need further investigation in co-infection settings.

\section{Conclusions}

This review revealed that praziquantel administrated at a repeated standard dose of $40 \mathrm{mg} / \mathrm{kg}$ was more efficacious than the standard single dose of $40 \mathrm{mg} / \mathrm{kg}$. The outcomes of praziquantel efficacy depended on whether it was mixed infection of $S$. haematobium and $S$. mansoni or a single focus of infection. The efficacy of praziquantel in mixed infection foci required at least two rounds of standard dose at three weeks interval. Praziquantel given at $60 \mathrm{mg} / \mathrm{kg}$ single dose was shown to be slightly more efficacious than other regimens. S. haematobium was shown to be more sensitive to praziquantel than S. mansoni. Praziquantel showed moderate efficacy in areas that had received multiple MDA. The review suggests that follow ups should be done in endemic area after mass drug administration as recently initiated in Zimbabwe by Mutapi and Mduluza (personal communication). The use of repeated doses of $40 \mathrm{mg} / \mathrm{kg}$ and the high dose $(60 \mathrm{mg} / \mathrm{kg})$ need further investigations before being recommended for use in control programmes in endemic areas of sub-Saharan Africa to prevent possible resistance to praziquantel. 


\section{Additional files}

Additional file 1: Multilingual abstracts in the six official working languages of the United Nations. (PDF $417 \mathrm{~kb}$ )

Additional file 2: Table S1. Summary of findings on the use of praziquantel against Schistosoma mansoni between 2008-2017 in sub-Saharan Africa. (DOCX 25 kb)

Additional file 3: Table S2. Summary of findings on the use of praziquantel against Schistosoma haematobium between 2008-2017 in sub-Saharan Africa. (DOCX 22 kb)

Additional file 4: Table S3. Summary of review of findings on the use of praziquantel on co-infection with Schistosoma haematobium and S. mansoni between 2008-2017 in sub-Saharan Africa. (DOCX 22 kb)

\section{Abbreviations}

CR: Cure rate; ERR: Egg reduction rate; GM: Geometric mean; MDA: Mass drug administration; PZQ: Praziquantel; WHO: World Health Organisation

\section{Acknowledgements}

The authors would like to acknowledge the College of Health Sciences (CHS) through CHS scholarship program at the University of KwaZulu-Natal for their financial support. This research was commissioned by the National Institute of Health Research using Official Development Assistance (ODA) funding. The views expressed in this publication are those of the author(s) and not necessarily those of the NHS, the National Institute of Health Research, or the Department of Health.

\section{Availability of data and materials}

Please contact author for any request.

\section{Authors' contributions}

MK, MC, SM conceptualized the study. MK did the literature search, analysis and drafted the manuscript; MC and SM guided the literature search and provided critical comments until final approval of the manuscript; all authors read and approved the final manuscript.

\section{Authors' information}

MK is a Medical Doctor and PhD candidate in the department of Public Health Medicine at the University of KwaZulu-Natal; MC is a Professor and Dean of research of Health Sciences in the KwaZulu-Natal University; SM is a Professor at the School of Life Sciences at the University of KwaZulu-Natal, Durban, South Africa.

\section{Ethics approval and consent to participate}

Not applicable.

\section{Consent for publication}

Not applicable.

\section{Competing interests}

The authors declare that they have no competing interests.

\section{Author details}

'Discipline of Public Health Medicine, Howard College, University of KwaZulu-Natal, P.O Box 4041, Durban, South Africa. ${ }^{2}$ College of Health Sciences, University of KwaZulu-Natal, Durban, South Africa. ${ }^{3}$ School of Life Sciences, University of KwaZulu-Natal, Durban, South Africa.

Received: 24 October 2017 Accepted: 6 June 2018

Published online: 05 July 2018

\section{References}

1. Steinmann P, Keiser J, Bos R, Tanner M, Utzinger J. Schistosomiasis and water resources development: systematic review, meta-analysis, and estimates of people at risk. Lancet Infect Dis. 2006;6(7):411-25.

2. World Health Organization. Investing to overcome the global impact of Neglected Tropical Diseases, Third WHO report on Neglected Tropical Diseases 2015. Geneva: World Health Organization; 2015.
3. Mahmoud AAF. Schistosomiasis and other trematode infections. In: Kasper DL, Braunwald E, Fauci AS, Hauser LS, Longo D, Jameson JL, editors. Harrison's principles of internal medicine. 16th ed. New York: McGraw-Hill; 2006.

4. Sturrock R. The control of schistosomiasis. Second report of the WHO expert committee: Geneva: World Health Organization. 1993;

5. French MD, Churcher TS, Gambhir M, Fenwick A, Webster JP, Kabatereine $\mathrm{NB}$, et al. Observed reductions in Schistosoma mansoni transmission from large-scale administration of praziquantel in Uganda: a mathematical modelling study. PLoS Negl Trop Dis. 2010;4(11):e897.

6. Ahmed AM, Abbas H, Mansour FA, Gasim Gl, Adam I. Schistosoma haematobium infections among schoolchildren in central Sudan one year after treatment with praziquantel. Parasit Vectors. 2012;5(1):1.

7. King CH, Olbrych SK, Soon M, Singer ME, Carter J, Colley DG. Utility of repeated praziquantel dosing in the treatment of schistosomiasis in highrisk communities in Africa: a systematic review. PLoS Negl Trop Dis. 2011; 5(9):e1321.

8. Belizario VY Jr, Amarillo MLE, Martinez RM, Mallari AO, Tai CMC. Efficacy and safety of $40 \mathrm{mg} / \mathrm{kg}$ and $60 \mathrm{mg} / \mathrm{kg}$ single doses of praziquantel in the treatment of schistosomiasis. J Pediatric Infect Dis Soc. 2008;3(1):27-34.

9. Coulibaly JT, Panic G, Silué KD, Kovač J, Hattendorf J, Keiser J. Efficacy and safety of praziquantel in preschool-aged and school-aged children infected with Schistosoma mansoni: a randomised controlled, parallel-group, doseranging. phase 2 trial. Lancet Glob Health. 2017;5(7):e688-e98.

10. Coles GC, Kinoti GK. Defining resistance in Schistosoma. Parasitol Today. 1997;13(4):157-8

11. Zwang J, Olliaro P. Efficacy and safety of praziquantel $40 \mathrm{mg} / \mathrm{kg}$ in preschool-aged and school-aged children: a meta-analysis. Parasit Vectors. 2017;10(1):47.

12. Utzinger J, N'Goran EK, N'Dri A, Lengeler C, Shuhua X, Tanner M. Oral artemether for prevention of Schistosoma mansoni infection: randomised controlled trial. Lancet. 2000;355(9212):1320.

13. De Clerca D, Vercruysse J, Kongs A, Verle P, Dompnier J, Faye P. Efficacy of artesunate and praziquantel in Schistosoma haematobium infected schoolchildren. Acta Trop. 2002:82(1):61-6.

14. Merrifield M, Hotez PJ, Beaumier CM, Gillespie P, Strych U, Hayward T, et al. Advancing a vaccine to prevent human schistosomiasis. Vaccine. 2016; 34(26):2988-91.

15. Brouwer KC, Ndhlovu PD, Wagatsuma Y, Munatsi A, Shiff CJ. Urinary tract pathology attributed to Schistosoma haematobium: does parasite genetics play a role? Am J Trop Med Hyg. 2003:68(4):456-62.

16. Gasmelseed N, Karamino NE, Abdelwahed MO, Hamdoun AO. AE. Genetic diversity of Schistosoma haematobium para-site IS NOT associated with severity of disease in an endemic area in Sudan. BMC Infect Dis. 2014;(14): 469-76

17. World Health Organization. Assessing the efficacy of anthelminthic drugs against schistosomiasis and soil-transmitted helminthiases 2013. Geneva: World Health Organization; 2013.

18. Muheki ET. The effect of one versus two praziquantel treatments on Schistosoma mansoni morbidity and re-infection along lake Vicrotiria in Uganda: MAKERERE UNIVERSITY; 2011

19. Haile S, Golassa L, Mekonnen Z. Prevalence of Schistosoma mansoni and effectiveness of Praziquantel in school children in Finchaa valley, Ethiopia J. Parasitol. Vector Biol. 2012:4(3):25-30.

20. Ojurongbe O, Sina-Agbaje OR, Busari A, Okorie PN, Ojurongbe TA, Akindele AA. Efficacy of praziquantel in the treatment of Schistosoma haematobium infection among school-age children in rural communities of Abeokuta. Nigeria. Infect Dis Poverty. 2014:3(1):30-7.

21. Senghor B, Diaw OT, Doucoure S, Sylla SN, Seye M, Talla I, et al. Efficacy of praziquantel against urinary schistosomiasis and reinfection in Senegalese school children where there is a single well-defined transmission period. Parasit Vectors. 2015:8(1):362

22. Munisi DZ, Buza J, Mpolya EA, Angelo T, Kinung'hi SM. The efficacy of single versus double praziquantel treatments on Schistosoma mansoni infections: ts implication on undernutrition and anaemia among primary schoolchildren in two on-shore communities, north-western Tanzania. Biomed Res Int. 2017:2017:7035025.

23. Webster BL, Diaw OT, Seye MM, Faye DS, Stothard JR, Sousa-Figueiredo JC, et al. Praziquantel treatment of school children from single and mixed infection foci of intestinal and urogenital schistosomiasis along the Senegal River Basin: monitoring treatment success and re-infection patterns. Acta Trop. 2013;128(2):292-302 
24. Tchuenté L-AT, Momo SC, Stothard JR, Rollinson D. Efficacy of praziquantel and reinfection patterns in single and mixed infection foci for intestinal and urogenital schistosomiasis in Cameroon. Acta Trop. 2013;128(2):275-83.

25. World Health Orgagamization. Report of a meeting to review the results of studies on the treatment of schistosomiasis in preschool-age children 2011 Geneva: World Health Organization; 2011.

26. Navaratnam A, Sousa-Figueiredo J, Stothard J, Kabatereine N, Fenwick A Mutumba-Nakalembe M. Efficacy of praziquantel syrup versus crushed praziquantel tablets in the treatment of intestinal schistosomiasis in Ugandan preschool children, with observation on compliance and safety. Trans R Soc Trop Med Hyg. 2012;106(7):400-7.

27. Nalugwa A, Nuwaha F, Tukahebwa EM, Olsen A. Single versus double dose praziquantel comparison on efficacy and Schistosoma mansoni re-infection in preschool-age children in Uganda: a randomized controlled trial. PLoS Negl Trop Dis. 2015;9(5):e0003796.

28. Mutapi F, Rujeni N, Bourke C, Mitchell K, Appleby L, Nausch N, et al. Schistosoma haematobium treatment in 1-5 year old children: safety and efficacy of the antihelminthic drug praziquantel. PLoS Negl Trop Dis. 2011; 5(5):e1143.

29. Sousa-Figueiredo JC, Betson M, Atuhaire A, Arinaitwe M, Navaratnam AM, Kabatereine NB, et al. Performance and safety of praziquantel for treatment of intestinal schistosomiasis in infants and preschool children. PLoS Negl Trop Dis. 2012;6(10):e1864.

30. Coulibaly JT, N'Gbesso YK, Knopp S, Keiser J, N'Goran EK, Utzinger J. Efficacy and safety of praziquantel in preschool-aged children in an area coendemic for Schistosoma mansoni and S. haematobium. PLoS Negl Trop Dis. 2012;6(12):e1917.

31. Garba A, Lamine MS, Djibo A, Tahirou A, Aouami MA, Alfari A, et al. Safety and efficacy of praziquantel syrup (Epiquante $\left.\right|^{\oplus}$ ) against Schistosoma haematobium and Schistosoma mansoni in preschool-aged children in Niger. Acta Trop. 2013;128(2):318-25.

32. Garba A, Lamine MS, Barkiré N, Djibo A, Sofo B, Gouvras AN, et al. Efficacy and safety of two closely spaced doses of praziquantel against Schistosoma haematobium and S. mansoni and re-infection patterns in school-aged children in Niger. Acta Trop. 2013;128(2):334-44.

33. Kabuyaya M, Chimbari MJ, Manyangadze T, Mukaratirwa S. Efficacy of praziquantel on Schistosoma haematobium and re-infection rates among school-going children in the Ndumo area of uMkhanyakude district, KwaZulu-Natal. South Africa. Infect Dis Poverty. 2017:6(1):83-91.

34. Sousa-Figueiredo JC, Pleasant J, Day M, Betson M, Rollinson D, Montresor A, et al. Treatment of intestinal schistosomiasis in Ugandan preschool children: best diagnosis, treatment efficacy and side-effects, and an extended praziquantel dosing pole. Internat Health. 2010;2(2):103-13.

35. Midzi N, Sangweme D, Zinyowera S, Mapingure M, Brouwer K, Kumar N, et al. Efficacy and side effects of praziquantel treatment against Schistosoma haematobium infection among primary school children in Zimbabwe. Trans R Soc Trop Med Hyg. 2008;102(8):759-66.

36. Erko B, Degarege A, Tadesse K, Mathiwos A, Legesse M. Efficacy and side effects of praziquantel in the treatment of schistosomiasis mansoni in schoolchildren in Shesha Kekele Elementary School, Wondo Genet. Southern Ethiopia. Asian Pac J Trop Biomed. 2012;2(3):235-9.

37. Valle C, Troiani AR, Festucci A, Pica-Mattoccia L, Liberti P, Wolstenholme A et al. Sequence and level of endogenous expression of calcium channel $\beta$ subunits in Schistosoma mansoni displaying different susceptibilities to praziquantel. Mol Biochem Parasitol. 2003;130(2):111-5.

38. Crellen T, Walker M, Lamberton PH, Kabatereine NB, Tukahebwa EM, Cotton $J A$, et al. Reduced efficacy of praziquantel against Schistosoma mansoni is associated with multiple rounds of mass drug administration. Clin Infect Dis. 2016:63(9):1151-9.

39. Tukahebwa EM, Vennervald BJ, Nuwaha F, Kabatereine NB, Magnussen P. Comparative efficacy of one versus two doses of praziquantel on cure rate of Schistosoma mansoni infection and re-infection in Mayuge District. Uganda. Trans R Soc Trop Med Hyg. 2013;107(6):397-404.

40. Ismail MM, Taha SA, Farghaly AM, El-Azony A. Laboratory induced resistance to praziquantel in experimental schistosomiasis. J Egypt Soc Parasitol. 1994; 24(3):685-95.

\section{Ready to submit your research? Choose BMC and benefit from:}

- fast, convenient online submission

- thorough peer review by experienced researchers in your field

- rapid publication on acceptance

- support for research data, including large and complex data types

- gold Open Access which fosters wider collaboration and increased citations

- maximum visibility for your research: over $100 \mathrm{M}$ website views per year

At BMC, research is always in progress.

Learn more biomedcentral.com/submissions 